\title{
Periapikal lezyonların yüksek çözünürlüklü ultrasonografi ile görüntülenmesinde etkili faktörlerin belirlenmesi ${ }^{*}$
}

\author{
Meryem Etöz(0000-0001-7222-0430 ${ }^{\alpha}$, Fatma Avcı (0000-0003-0863-0819) $^{\alpha}$, Emin Murat Canger(0000-0002-0798-9355) ${ }^{\alpha}$, \\ Zekeriya Taşdemir(0000-0003-0359-2462) ${ }^{\beta}$
}

Selcuk Dent J, 2020; 7: 213-219 (Doi: 10.15311/selcukdentj.487664)

Bașvuru Tarihi: 26 Kasım 2018 Yayına Kabul Tarihi: 09 Mayıs 2019

\section{öz}

Periapikal lezyonların yüksek çözünürlüklü ultrasonografi ile görüntülenmesinde etkili faktörlerin belirlenmesi

Amaç: $\mathrm{Bu}$ çalışmada panoramik (PR) ve periapika radyograflarda (PAR) izlenen periapikal patolojilerin ultrasonografi (USG) ile değerlendirilmesinde yaş, cinsiyet, lezyon boyut ve lokalizasyon gibi olası etkilerin belirlenmesi amaçlanmıştır. Ayrıca lezyonun boyutu ile USG de vaskülarizasyon varlığı arasındaki ilişkinin belirlenmesi de amaçlanmıştır.

Gereç ve Yöntem: Çalışma 46 birey üzerinde yürütüldü. Periapikal lezyonların (PAL) ilişkili olduğu dişler, her bir çene için anterior, premolar ve molar dişler olarak altı grup halinde sınıflandırıldı. PAL'lerin periapikal radyograflardaki mezio-distal (MD) boyutları, $<5 \mathrm{~mm}, 6-10 \mathrm{~mm}$ arası ve $>10 \mathrm{~mm}$ olacak şekilde üç grup olarak sınıflandırıldı. PAL'lerin MD boyutları üç farklı görüntüleme yöntemiyle (PAR, PR ve USG) ölçüldü ve ikill uyumları karşıslaştıııldı. USG incelemelerinin tamamı yüksek çözünürlüklü ultrasonografi cihazı B-Mod ve yüksek frekansl lineer tarama probları kullanılarak gerçekleştirildi. Renkli doppler USG ile de PA lezyonların vaskülarizasyonları değerlendirildi.

Bulgular: PAL'lerin lokalizasyonlarının, USG'de görünebilir olmaları üzerinde etkili olduğu saptandı $(p<0.001)$. Maksiller anterior bölgedeki lezyonların görünürlülüğünün en fazla olduğu ancak maksiler premolar ve mandibular molar bölgedeki lezyonların USG ile görüntülenemediği izlendi. Lezyon boyutu ile renkli doppler USG vaskülarizasyon bulguları arasında bir ilişki izlenmedi.

Sonuç: Her üç teknikte de (PR, PAR ve USG) lezyonların maksimum MD boyut ölçümlerinin birbiriyle uyumlu olduğu görüldü. Lezyon karakteristiğinin lezyon boyutu ile ilişkilendirilemeyeceği gözlendi. USG, görüntülenebilen periapikal lezyonların takibinde kullanılabilecek alternatif bir teknik olabilir.

\section{ANAHTAR KELIMELER}

Panoramik radyografi, periapikal lezyon, periapikal radyografi, ultrasonografi

\section{ABSTRACT}

Determination of effective factors in Imaging of periapical lesions with high resolution ultrasonography

Background: In this study, it was aimed to determine possible effects of age, gender, dimension and localization of lesions on ultrasonographic (USG) evaluation of periapical lesions that have been seen on periapical (PA) and panoramic radiographs (PAR). In addition, investiagation of a possible relationship between the dimension of the lesion and the presence of vascularisation was within the aims.

Methods: The study was carried on 46 individuals. The teeth in relation with lesion was classified as 6 groups as anterior, premolar and molar teeth according to the sides and jaws. The mesio-distal (MD) dimension of the periapical lesions (PAL) were classified as $<5 \mathrm{~mm}$, between $6-10 \mathrm{~mm}$ and $>10 \mathrm{~mm}$. PALs' MD dimensions assessed with three different imaging methods (PAR, PR ve USG) and binary compatibilities was compared. The whole USG examinations were performed with a simultaneous B-mode high resolution ultrasonic device and using high frequency probes. MD size of PALs that were visualized ultrasonographically were measured and recorded. Vascularization of PALs was also evaluated with color doppler USG.

Results: The localisations of PALs' were effective on the visualisation on USG $(p<0.001)$. While the anterior maxillary region was the most visible region, visbility of the maxillary and mandibulary premolar and molar regions were not possible. Also there was not any relationship between lesion dimension and vascularisation findings.

Conclusion: It has been shown that measurements of maximum MD dimensions were in concordance with each other in all three techniques (PR, PAR ve USG). It has been observed that there was no association betweeen characteristics and dimensions of lesions. In conclusion USG might be thought as an alternative imaging technique for follow-up of periapical lesions.

\section{KEYWORDS}

Panoramic radiography, periapical lesion, periapical radiography, ultrasonography

\footnotetext{
* Çalışma, "Oral Diagnoz ve Maksillofasiyal Radyoloji Derneği 2. Uluslararası Kongresi, 7. Bilimsel Toplantısı. 13-15 Nisan 2017 Eskisehir/Türkiye" de Sözlü Bildiri olarak sunulmuştur.

${ }^{\alpha}$ Erciyes Üniversitesi Diş Hekimliği Fakültesi Ağız Diş ve Çene Radyolojisi Anabilim Dalı, Kayseri

$\beta$ Erciyes Üniversitesi Diş Hekimliği Fakültesi Periodontoloji Anabilim Dalı, Kayseri 
İnsan vücudunun görüntülenmesinde kullanılan ultrasonografi (USG), vücuda yüksek frekanstaki ses dalgalarının gönderilmesi ve bunların farklı doku yüzeylerinden yansımalarının saptanması temeline dayanan bir görüntüleme tekniğidir. ${ }^{1}$ USG tekniğinin tekrarlanabilir, basit, düşük malyetli, invaziv olmayan bir yöntem olması, teknik açıdan sürekli geliştirilebilmesi ve en önemlsi de iyonizan radyasyon kullanımadan uygulanıyor olması medikal radyolojide olduğu gibi diş hekimliği radyolojisinde de kullanım alanı bulmasını sağlamıştır. ${ }^{2}$

USG dalgalarının kalın kortikal yapılara penetre olamamasından dolayı kemik içi lezyonların görüntülenemediği bildirilmiştir. ${ }^{3}$ Ancak çenelerde görülen birçok kemik içi lezyon bukkal kortikal kemikte incelmeye veya perforasyona sebep olmaktadır. ${ }^{4}$ Maksiler ve mandibular kemik içi lezyonların bukkal kortikal kemikte incelmeye veya perforasyona neden olduğu vakalarda USG ile görüntülenebildiğini bildiren birçok araştırma mevcuttur. , $^{3,6,6,7}$

USG ile görüntülenebilen kemik içi lezyonların boyutlarının ölçümü mümkün olup transduserin transversal olarak konumlandırımasıyla lezyonun bukkolingual /palatinal ve mesio-distal (MD) boyutu; transduserin longitudinal düzlem üzerinde yönlendirilmesiyle de lezyonun supero-inferior

belirlenebilmektedir. ${ }^{8,9}$

(SI) boyutu

USG'de görüntüleri elde edilen kemik içi lezyonlar karakteristiklerine göre kistik, semisolid ve solid olmak üzere üç şekilde sınıflandırılır. ${ }^{10}$ USG ve renkli doppler USG ile yapılan çalışmalarda periapikal lezyon (PAL) karakteristiğini belirlemede doppler USG'nin yararlı bir teknik olduğu belirtilmiş ve vaskülarizasyon gösteren lezyonlar solid, sıvı içeriği olanlar kistik ve hem kistik hem de solid USG bulgusu gösteren kombine lezyonlar semisolid lezyonlar olarak tanımlanmaktadır. 6,11

$\mathrm{Bu}$ çalışmada panoramik ve periapikal radyograflarda (PAR) izlenen periapikal patolojilerin USG ile görüntülenebilirliliğinin incelenmesi; lezyonun görünürlülüğüne yaş, cinsiyet, PAL'in boyut ve lokalizasyonunun etkisinin belirlenmesi; ayrıca lezyon boyutu ile doppler USG'de lezyonlarda vaskülarizasyon varlığı arasındaki ilişkinin tanımlanması amaçlanmıştır.

\section{GEREÇ VE YÖNTEM}

$\mathrm{Bu}$ araştırma için Erciyes Üniversitesi Klinik Araştırmaları Etik Kurulu tarafından onay alındı. (2011-KAEK-80) Çalışmaya katılan tüm bireylerden, araștırmanın içeriğ, amacı, uygulanacak ișlem anlatılarak yazılı onam alındı.

Araştırma Erciyes Üniversitesi Diş Hekimliği Fakültesi Ağız Diş ve Çene Radyolojisi Anabilim Dalı'na farklı şikâyet ve nedenlerle başvuran, radyografik bulgular ile periapikal lezyonu olduğu belirlenen 46 birey ile gerçekleştirildi.

Çalışmada kullanılan panoramik görüntülerin tamamı İnstrumentarium Dental Orthopantomograph OP200 D (67 kV, 16 $\mathrm{mA}$ doz ayarlaması ve 14.1 sn ışınlama süresi) cihazı ile alındı. Dijital periapikal radyograflar Kodak 2100 intraoral x-ray sistemi ile (60 kV, $7 \mathrm{~mA}$ doz ayarlaması ve $0.16 \mathrm{sn}$ ışınlama süresi) açıortay tekniği kullanılarak elde edildi. Görüntülerin tamamı karanlık odada 1280x1024 çözünürlükteki bilgisayar ekranında (DELL E190S/China) değerlendirildi. Lezyonların maksimum MD boyutu panoramic ve periapikal radyograflarda ölçülüp ilişkili olduğu diş numarası ile beraber kaydedildi (Resim 1).
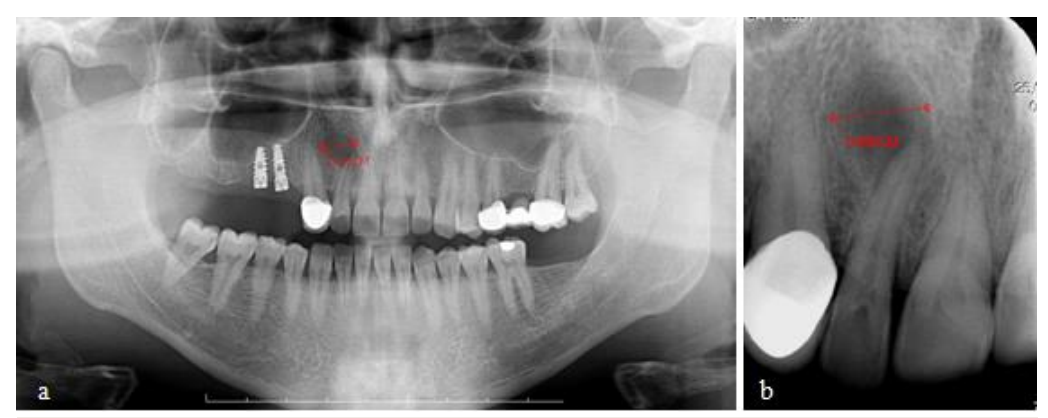

Resim 1.

a) Lezyonun panoramik radyografta mesio-distal ölçümü, b) Lezyonun periapikal filmde mesio-distal boyutu

PAL'lerin ilişkili olduğu dişler maksilla ve mandibula için ayrı ayrı anterior, premolar ve molar olmak üzere altı grupta kategorize edilerek incelendi. PAL'lerin PAR'lardaki MD boyutları üç sınıfa ayrlarak $(<5 \mathrm{~mm} ; 6-10 \mathrm{~mm}$ ve $>10 \mathrm{~mm})$ USG'deki görünürlülüğüne etkisi incelendi.

USG incelemelerinin tamamı (Aplio $^{\mathrm{TM}}$ 500; ToshibaMedicalSystems Corporation, Otawara, Japan) B-Modu ve yüksek frekanslı (7-18 MHz; PLT-1005BT) veya (14-7.2 MHz; PLT1204BT) lineer tarama probları kullanılarak, 5 yıllık USG deneyimi olan ağız diş ve çene radyolojisi uzmanı (ME) tarafından gerçekleştirildi. Probla cilt arasında hava kalmasını önlemek amacıyla su bazı ıel uygulandı. Ultrasonografik olarak prob ilişkili bölgeye transvers yönde konumlandırılarak görüntülenen PAL'lerin maksimum MD boyutu ölçülüp kaydedildi. (Resim 2b, Resim 3b, Resim 4b, Resim 5b) Renkli Doppler USG'de doku morfolojisi gri skalada, eş zamanlı olarak renkli modda gösterildi. PAL'lerin internal renk kodlaması, hareketli eritrositlerden alınan sinyaller, akımın yönüne göre mavi ya da kırmızı renkte kodlanarak görüntü elde edildi ve kaydedildi (Resim 2c, Resim 3c, Resim 4c, Resim $5 c)$. 


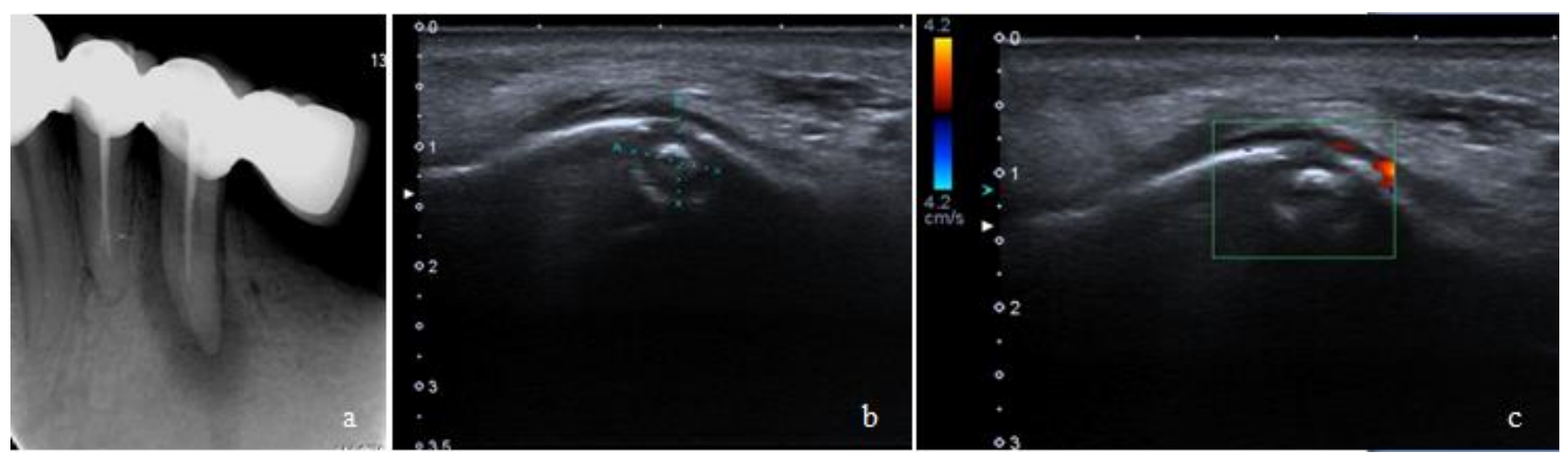

Resim 2.

a) Periapikal filmde 35 nolu dişte periapikal lezyon, b) USG'de mix görüntü veren periapikal lezyon üzerinde yapılan mesio-distal ve antero-posterior ölçüm, c) Renkli doppler tetkik sonrası elde edilen görüntüde lezyonun avaskülar olduğu gözlenmiştir; kırmızı renkli bölgeler lezyon dışı bölgede vaskülarizasyon bulunduğunu göstermektedir
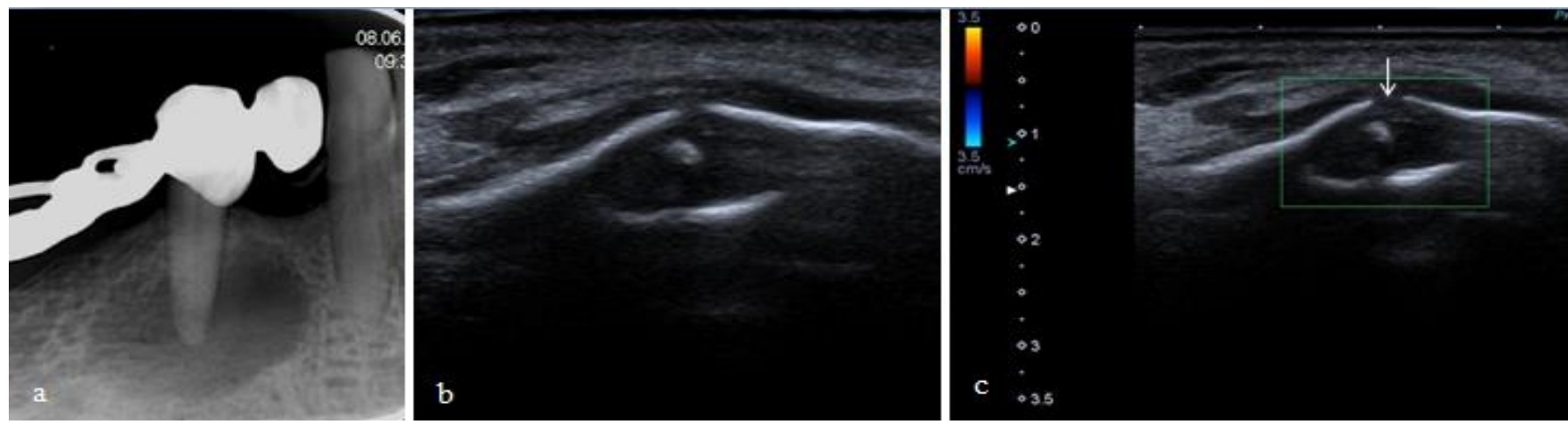

Resim 3.

a) Periapikal filmde 45 nolu diște periapikal lezyon lezyon, b) USG'de mix görüntü veren periapikal lezyonun renkli doppler tetkikleri sonrası elde edilen görüntüde lezyonun avasküler olduğu ve vestibül kortikal kemikte perforasyon varlığı (ok) izlenmektedir.
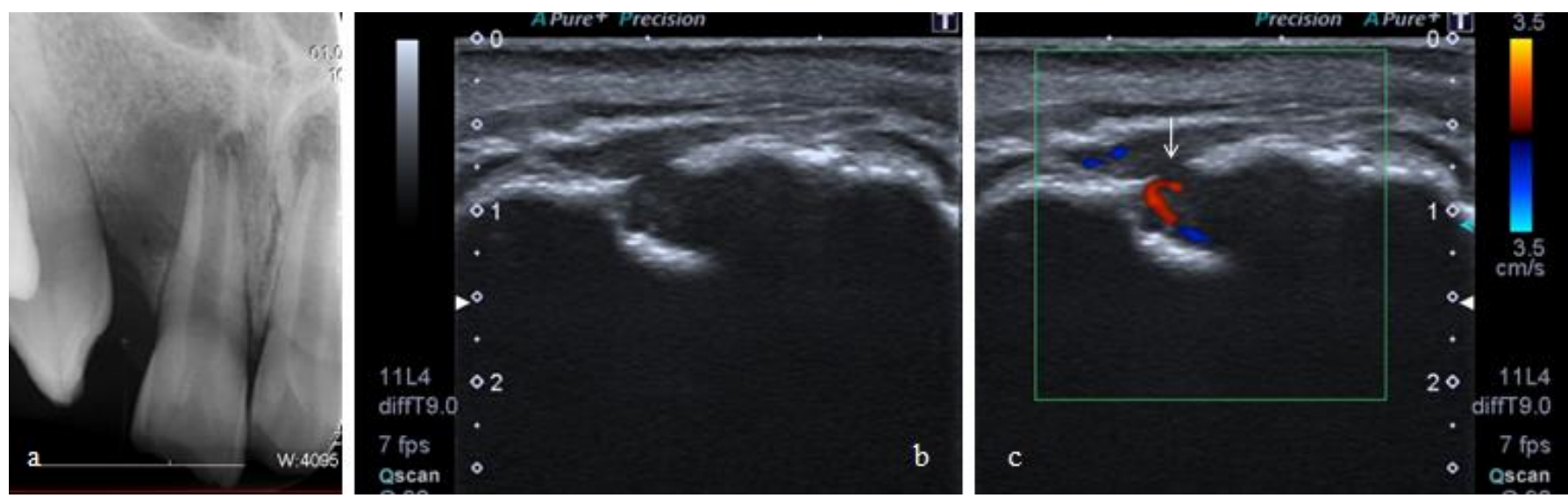

Resim 4.

a) Periapikal filmde 11 nolu dişte periapikal lezyon, b) Ultrasonografide anekoik görüntü veren periapikal lezyon, renkli doppler tetkikleri sonrası elde edilen görüntüde gözlenen vaskülarizasyon ve vestibül kortikal kemikte perforasyon (ok) 

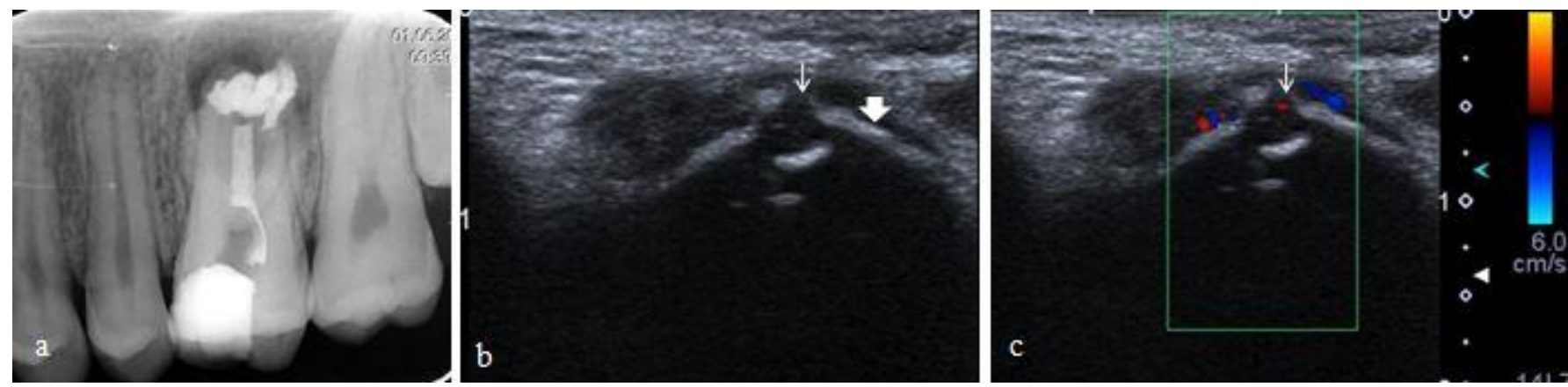

Resim 5.

a) Periapikal filmde 26 nolu dişte periapikal lezyon, b) Ultrasonografide anekoik görüntü veren periapikal lezyon, vestibül kortikal kemikte perforasyon (ince ok) ,yumuşak dokudaki lezyon (kalın ok) c) renkli doppler tetkikleri sonrası elde edilen görüntüde gözlenen vaskülarizasyon ve vestibül kortikal kemikte perforasyon (ince ok)

PAL'lerin MD boyutları üç farklı görüntüleme yöntemiyle (PAR, PR ve USG) ölçüldü ve ikili uyumları karşılaştıııld.

İstatistiksel incelemeler IBM SPSS Statistics 20 (Statistical PackagefortheSocialSciences) istatistiksel analiz paket programları kullanılarak yapıldı. Kategorik değişkenler "n" ve "\%" değerleri ile gösterildi ve Pearson ki-kare testi exact metod kullanılarak karşılaştırıldı. Sayısal veriler korelasyon testleri kullanılarak karşıllaştııılı. Anlamlılık düzeyi $p<0.05$ olarak kabul edildi.

\section{BULGULAR}

Çalışmamızda 29 kadın ve 17 erkek, 46 PALli bireyin yaş ortalamaları için sırasıyla; $19-76$ yaş (ort 42 yaş; 13.3 SD) ve 15-62 (ort 31 yaş; 15.6 SD) bulundu. Hastaların yaş ve cinsiyetlerinin lezyonların USG'de ki görünürlülüğüne etkilerinin olmadığı saptandı ( $p=0.640$; Tablo 1 , Tablo 2 ).

PALlerin lokalizasyonlarının USG'de ki görünürlülükte etkili olduğu ve bu farklılığın istatistiksel olarak da anlamlı olduğu saptandı $(p<0.001)$. Maksiller anterior bölgedeki lezyonların görünürlülüğünün en fazla olduğu ancak maksiler premolar ve mandibular molar bölgedeki lezyonların USG ile görüntülenemediği izlendi. Maksiler ve mandibular premolar ve molar bölgede mevcut lezyonların USG görünürlülüğünde fark izlenmedi (Tablo 3).

Tablo 1.

Çalışmada yer alan bireylerin cinsiyet ve yaş dağılımları

\begin{tabular}{|lccccc|} 
& N & min & max & ort & Std. Dev. \\
\hline Kadın & 29 & 19 & 76 & 42 & 13.3 \\
\hline Erkek & 17 & 15 & 62 & 31 & 15.6 \\
\hline Toplam & 46 & 15 & 76 & 38 & 15.2 \\
\hline
\end{tabular}

N: birey sayısı. min: minimum yaş. max: maximum yaş ort: bireylerin ortalama yaşları. std.dev: standart deviasyon
Tablo 2.

\section{Cinsiyetin periapikal lezyonların ultrasonografik görünürlülüğüne etkisi}

\begin{tabular}{|lcc|c|}
\hline USG görünürlülük & Kadın & Erkek & Toplam \\
\hline görünmüyor & $10(34.5)$ & $8(47.1)$ & $18(39.1)$ \\
\hline görünüyor & $19(65.6)$ & $9(52.9)$ & $28(60.9)$ \\
\hline Toplam & $29(100)$ & $17(100)$ & $46(100)$ \\
\hline
\end{tabular}

$(p=0.640)$ istatistiksel olarak anlamlı fark izlenmedi. Veriler $n$ (\%) olarak gösterilmiştir.

\section{Tablo 3.}

\section{Periapikal lezyonların lokalizasyonlarının ultrasonografideki görünürlülük dağılımları}

\begin{tabular}{lccccccc}
$\begin{array}{l}\text { USG } \\
\text { görünürlülük }\end{array}$ & Max ant & $\begin{array}{c}\text { Max } \\
\text { premolar }\end{array}$ & $\begin{array}{c}\text { Max } \\
\text { molar }\end{array}$ & $\begin{array}{c}\text { Mand } \\
\text { ant }\end{array}$ & $\begin{array}{c}\text { Mand } \\
\text { premolar }\end{array}$ & $\begin{array}{c}\text { Mand } \\
\text { molar }\end{array}$ & Toplam \\
\hline görünmüyor & $1(8.3)$ & $3(100)$ & $2(40)$ & $0(0)$ & $4(44.4)$ & $8(100)$ & $18(39.1)$ \\
& $\mathrm{a}$ & $\mathrm{b}$ & $\mathrm{a}, \mathrm{b}$ & $\mathrm{a}$ & $\mathrm{a}, \mathrm{b}$ & $\mathrm{b}$ & \\
\hline & $11(91.7)$ & $0(0)$ & $3(60)$ & $9(100)$ & $5(55.6)$ & $0(0)$ & $28(60.9)$ \\
\hline görünüyor & $\mathrm{a}$ & $\mathrm{b}$ & $\mathrm{a}, \mathrm{b}$ & $\mathrm{a}$ & $\mathrm{a}, \mathrm{b}$ & $\mathrm{b}$ & \\
\hline Toplam & $12(100)$ & $3(100)$ & $5(100)$ & $9(100)$ & $9(100)$ & $8(100)$ & $46(100)$
\end{tabular}

Veriler $n(\%)$ olarak gösterilmiştir. $(p<0,001)$ gruplar arasında istatistiksel olarak anlamlı fark izlendi. $a, b$ : istatistiksel olarak fark izlenen gruplar farklı harflerle kodlandı.

\section{Tablo 4.}

\section{Periapikal \\ lezyonların ultrasonografideki görünürlülük dağılımları}

\begin{tabular}{lcccc} 
& \multicolumn{5}{c}{ M-D Boyutu } \\
USG \\
görünürlülük & $<5$ & $6-10$ & $>10$ & Toplam \\
\hline \multirow{2}{*}{ görünmüyor } & $6(31.6)$ & $11(50)$ & $1(20)$ & $18(39.1)$ \\
\cline { 2 - 5 } & $\mathrm{a}$ & $\mathrm{a}$ & $\mathrm{a}$ & \\
\hline görünüyor & $13(68.4)$ & $11(50)$ & $4(80)$ & $28(60.9)$ \\
\hline Toplam & $\mathrm{a}$ & $\mathrm{a}$ & $\mathrm{a}$ & \\
\hline & $19(100)$ & $22(100)$ & $5(100)$ & $46(100)$
\end{tabular}

PA M-D boyutu: Periapikal radyogtafta ölçülen periapikal lezyonun $\mathrm{mm}$ cinsinden mezio-distal boyutu. $p=0,380$ istatistiksel olarak anlamlı fark izlenmedi. Veriler n (\%) olarak gösterilmiştir. 
Lezyonların periapikal radyograflardaki MD boyutunun USG görünürlülüğüne etkisi lezyon boyutları $<5 \mathrm{~mm}$; 6-10 mm ve $>10 \mathrm{~mm}$ olarak üç ayrı grupta incelendi ve gruplar arası USG görünürlülüğü açısından fark gözlenmedi ( $p=0.380$; Tablo 4).

PAL'lerin MD boyutları üç farklı görüntüleme yöntemiyle (PAR, PR ve USG) ölçüldü ve uyumları karşılaştırıldı. PAR-PR, USG-PR, USG-PAR grupları arasındaki korelasyon katsayıları sırasıyla 0.942 $(p<0.001), 0.885(p<0.001)$ ve $0.870 \quad(p<0.001)$ bulundu. Her üç teknik de lezyonların maksimum MD boyut ölçümünde uyumlu olup bu sonuç istatistiksel olarak anlamlıydı (Tablo 5).

PA lezyonların maksimum MD boyutu $<5 \mathrm{~mm}$; 6-10 $\mathrm{mm}$ ve $>10 \mathrm{~mm}$ üç ayrı gruba ayrılarak renkli doppler USG'de vaskülarizasyon gösterip göstermediği incelendi. MD boyutu $<5$ olan lezyonlarda \% 84.2'sinde vaskülarizasyon izlenmezken; boyutu 6-10 ve $>10$ olan lezyonlarda bu oran sırasıyla \% 81.8 ve $\% 80$ bulundu. Lezyon boyutu ile renkli doppler USG vaskülarizasyon bulguları arasında bir ilişki izlenmedi $(p=0.270$; Tablo 6).

Tablo 5.

\section{Periapikal lezyonların mesio-distal boyutlarının üç farklı yöntemle uyumunun karşılaştırması}

\begin{tabular}{|l|cc|c|}
\hline $\begin{array}{l}\text { Korelasyon } \\
\text { katsayıları }\end{array}$ & PAN-PA & USG-PAN & USG-PA \\
\hline $\mathrm{r}$ & 0.942 & 0.885 & 0.870 \\
\hline $\mathrm{p}$ & $\mathrm{P}<0.001$ & $\mathrm{P}<0.001$ & $\mathrm{P}<0.001$ \\
\hline
\end{tabular}

PAN: panoramik radyografta ölçülen periapikal lezyonun $\mathrm{mm}$ cinsinden mezio-distal boyutu. PA: periapikal radyogtafta ölçülen periapikal lezyonun mm cinsinden mezio-distal boyutu. USG: B-mod ultrasonografide ölçülen periapikal lezyonun $\mathrm{mm}$ cinsinden meziodistal boyutu.

Tablo 6.

Lezyonların mesio-distal boyutunun renkli doppler ultrasonografi ile vaskülarizasyonları arasındaki ilişki

\begin{tabular}{lcccc|}
\multicolumn{5}{c}{ PA M-D boyutu } \\
$\begin{array}{l}\text { Doppler USG } \\
\text { vaskülarizasyon }\end{array}$ & $<5$ & $6-10$ & $>10$ & Toplam \\
\hline yok & $16(84.2)$ & $18(81.8)$ & $4(80)$ & $38(82.6)$ \\
\hline & $\mathrm{a}$ & $\mathrm{a}$ & $\mathrm{a}$ & \\
\hline var & $3(15.8)$ & $4(18.2)$ & $1(20)$ & $8(17.4)$ \\
\hline Toplam & $\mathrm{a}$ & $\mathrm{a}$ & $\mathrm{a}$ & \\
\hline & $19(100)$ & $22(100)$ & $5(100)$ & $46(100)$ \\
\hline
\end{tabular}

PA M-D boyutu: Periapikal radyogtafta ölçülen periapikal lezyonun $\mathrm{mm}$ cinsinden mezio-distal boyutu. $(p=0.270)$ istatistiksel olarak anlamlı fark izlenmedi. Veriler $n$ (\%) olarak gösterilmiştir.

\section{TARTIŞMA}

Klinik ve deneysel çalışmalarda elde edilen verilere göre sonografik muayene sonrasında ultrasonografik dalgaların bilinen bir yan etkisinin olmaması, konvansiyonel radyograflara kıyasla iyonize radyasyon içermemesi, klinik tecrübe ile kolay uygulanabilirlik ve hasta için rahatsız edici olmayan bir teknik olmasından dolayı tekrarlanabilir olduğu bildirilmiştir. ${ }^{6,7}$

Konvansiyonel radyografi iki boyutlu görüntüleme sunarken, konvansyonel USG le transversal ve longtüdnal değerlendirme yapılabilir, radyografinin aksine USG süperimpozisyonlara neden olmaz ve istenilen bölgenin eş zamanlı görüntülenebilmesine olanak sağlamaktadır. ${ }^{12}$

USG; son zamanlarda maksillofasiyal görüntülemede de kullanılmakta olup, baş-boyun lezyonlarında tanısal amaçla kullanımı geniş bir kabul görmüştür. ${ }^{5}$ Baş-boyun bölgesindeki enflamatuar yumuşak doku hastalıklarında, lenf nodlarının varlığının belirlenmesinde, fasiyal apselerin varlığını ve kapsamını görüntülemede kullanılmaktadır. ${ }^{13}$ Birçok obstrüktif, inflamatuar ve tümöral lezyon USG ile tespit edilip, ayırıcı tanıları yapılabilir. Kistik şişlikler, apseler, benign ve malign lezyonlar ayırt edilebilir. ${ }^{6}$ Yüksek çözünürlüklü ultrasonografi, tümörlerin cerrahi sınırlarının ve tümör kalınlığının değerlendirilmesinde de kullanılmaktadır. ${ }^{14}$ Oral malign tümör vakalarında ise bölgesel lenf nodu metastazlarının tespitinde etkilidir. Güncel literatür USG'nin çene kemiklerinde görülen lezyonların tanı ve tespitinde de yararlı bir görüntüleme yöntemi olduğunu ortaya koymuştur. ${ }^{4-8,11}$

Periapikal lezyonların USG ile değerlendirildiği çalışmalar genellikle lezyonların karakteristiğini belirlemeye yönelik olup $^{6,7,11,12,16}$ lezyonların USG yöntemi ile görünürlülüğünü etkileyen faktörlerin incelendiği çalışmaya rastlanılmamıştır. Önceki klinik çalışmalarda USG'nin periradiküler lezyonların değerlendirilmesinde yararlı bir teknik olduğu ve lezyonların boyutlarının bu teknikle ölçülebildiği bildirilmiştir. ${ }^{3,6,7}$ Raghav ve ark. ${ }^{16}$ nın 21 PAL'li hasta ile yaptığı çalışmada konvansiyonel ve dijital radyograflarda lezyonların MD ve SI boyutu ölçülmüş ve USG'de ölçülen MD, SI boyutları ile karşılaştırılarak lezyon boyutlarının USG'de konvansiyonel ve dijital radyograflardan daha küçük saptandığını bildirmişlerdir. Bunun sebebinin lezyonların lateral kemik duvarlarının akustik gölgelenmeye sebep olması ve ölçüm noktalarının USG tekniği ile tam olarak belirlenememesi olarak değerlendirmişlerdir. Bu nedenle USG tekniğinin operatöre bağlı olma, lezyonu bazı landmarklardan (diş kökleri gibi) dolayı spesifik bir bölgeyle ilişkilendirmenin zor olması ve labial kortikal kemikte incelme veya fenestrasyon olmadığı takdirde lezyonun görüntülenememesinin USG tekniğinin kısıtılıkları olduğunu belirtmişlerdir. Goel ve ark. ${ }^{17} 30$ periapikal lezyonun ultrasonografik (MD, SI ve Antero-Posterior) ve konvansiyonel radyografik tetkiklerle (MD ve $\mathrm{Sl}$ ) 
boyutlarını karşılaştırmışlardır. Sundukları çalışmada lezyonların MD ölçümlerinde anlamlı bir fark gözlenmezken, SI boyutlarında anlamlı fark gözlenmiştir. Onlar da bu farkın lezyonların lateral kemik duvarlarının akustik gölgelenmeye sebep olması ve ölçüm noktalarının tam olarak belirlenememesinden kaynaklanabileceğini düşünmüşlerdir. Goel ve ark. ${ }^{17}$ bu çalışmasında çenelerin posterior bölgelerdeki kalın bukkal kemik varlığından dolayı lezyonların görüntülenmesinde kısıtııığın mevcut olduğunu ve yeni probların geliştirilmesi gerekliliğinden bahsetmişlerdir. Bizim çalışmamızda ise her üç teknik ile lezyonların ölçülen MD boyutları uyumlu olup bu sonuç istatistiksel olarak da anlamlıydı. Anatomik kısıtılıklardan dolayı özellikle üst anterior bölgede probun longitudinal oryantasyonu çok mümkün olmadığı için SI boyutu ölçülmemiştir. Ayrıca ağız içi prob olarak kullanılan hockey-stick şekilli intraoperatif probların dişlerin hem vestibul hem de palatal/lingual yüzeylerde kullanımında rijit yapılarından dolayı birçok kısıtılık mevcuttur. Bu nedenle biz de yukarıda bahsedilen araştırmacıların görüşlerine katılıyor ve ağız içi probların geliştirilmesinin daha ergonomik olacağı kanısındayız.

USG ve renkli doppler tekniği ile PAL'li dişlerde apikal granulom ve periapikal kist ayırıcı tanısı üzerne yapılan çalışmalarda araştırmacılar konvansiyonel radyografiye göre USG'nin histopatolojik tanı ile doğrulanmış yüksek güvenirlilikte olduğunu bildirmişlerdir. ${ }^{15,17,18}$ Buna karşılık Tikku ve ark. ${ }^{19}$ ortalama 1.6 mm'nin altında kortikal kemik kalınlığı bulunan lezyonların USG ile doğru teşhis edildiğini ancak çevresinde 1.6 mm'ye eşit ve daha kalın kortikal kemik bulunan lezyonların teşhis doğruluğunun \% 65 'e düştüğünü bildirmişlerdir. Ayrıca araştırmacılar 30 lezyondan 7 tanesinin USG ile görüntülenemediğini bunun nedeninin de mandibular ve maksillar molar ve premolar bölgelerdeki kalın kortikal kemik varlığı nedeniyle olabileceğini belirtmişlerdir. Bizim çalışmamızda ise maksiler ve mandibular anterior dişler sırasıyla \% 91.7 ve $\% \quad 100$ oranında USG ile görüntülenirken maksiler premolar ve mandibular molar dişler ile ilişkili lezyonların hiçbiri USG ile görüntülenememiştir. Bunun yanında çalışmamızda lezyonların MD boyutunun renkli doppler USG ile vaskülarizasyonları arasındaki ilişki incelenmiş olup lezyonun karakteristiğinin (solid ya da kistik oluşu) lezyonun MD boyutu ile ilişkili olmadığı gözlenmiştir.

USG, Renkli Doppler görüntüleme ve konvansiyonel radyografinin endodontik kökenli periapikal lezyonların cerrahi sonrası iyileşmesini izlemedeki etkinliğinin değerlendirildiği bir araştırmada periapikal cerrahi uygulanan 15 hasta rastgele seçilmiştir. Postoperatif iyileşme tüm hastalarda 1. hafta ve 6 . ayda ultrasonografi, renkli Doppler görüntüleme ve konvansiyonel radyografi ile izlenmiş ve bulgular üç görüntüleme tekniğinin etkinliğini değerlendirmek için analiz edilmiştir. 6. ayda ultrason ve renkli Doppler görüntüleme cerrahi bölgedeki sert doku iyileşmesinde değişiklik tespit etmede konvansiyonel radyografiden anlamlı olarak daha üstün bulunmuştur. ${ }^{20} \mathrm{Bu}$ ve benzeri çalışmalar, ultrason ve renkli Doppler görüntülemenin endodontik kökenli periapikal lezyonların cerrahi sonrası iyileşmesini izlemede geleneksel radyografiyi destekleme potansiyeline sahip olduğunu göstermektedir.

\section{SONUÇ}

Sonuç olarak sunulan çalışmada:

- PAL'lerin USG görünürlülüğünde yaş ve cinsiyetin etkisinin olmadığı;

- PAL'lerin PAR'lardaki MD boyutlarının USG görünürlülüğünde belirleyici olmadığı

- Lezyonların lokalizasyonunun ise USG görünürlülüğünde etkili olduğu bulundu.

- Her üç tekniğin de (PR, PAR ve USG) lezyonların MD boyut ölçümünde birbiriyle ikili karşılaştırmalarında uyumlu olup görüntülenebilen periapikal lezyonların takibinde kullanılabilecek alternatif bir teknik olabilir.

- Lezyon boyutu ile renkli doppler USG vaskülarizasyon bulguları arasında bir ilişki izlenmedi ve lezyon karakteristiğinin lezyon boyutu ile ilişkilendirilemeyeceği gözlendi. 


\section{KAYNAKLAR}

1. Kossoff, G., Basic physics and imaging characteristics of ultrasound. World J Surg, 2000; 24: 2: 134-42.

2. Shah, N., N. Bansal, and A. Logani, Recent advances in imaging technologies in dentistry. World J Radiol, 2014; 6: 794-807.

3. Gundappa, M., S.Y. Ng, E.J. Whaites, Comparison of ultrasound, digital and conventional radiography in differentiating periapical lesions. Dentomaxillofac Radiol, 2006; 35: 326-33.

4. Lauria L, Curi MM, Chammas MC, Pinto DS, Torloni $\mathrm{H}$., Ultrasonography evaluation of bone lesions of the jaw. Oral Surg Oral Med Oral Pathol Oral Radiol Endod, 1996; 82: 351-7.

5. Ishii J, Nagasawa $H$, Wadamori $T$, Yamashiro $M$, Ishikawa $\mathrm{H}$, Yamada $\mathrm{T}$, Ultrasonography in the diagnosis of palatal tumors. Oral Surg Oral Med Oral Pathol Oral Radiol Endod, 1999; 87: 39-43.

6. Cotti E, Campisi G, Ambu R, Dettori C. Ultrasound real-time imaging in the differential diagnosis of periapical lesions. Int Endod J, 2003; 36: 556-63.

7. Cotti E, Campisi G, Garau V, Puddu G., A new technique for the study of periapical bone lesions: ultrasound real time imaging. Int Endod J, 2002; 35: 148-52.

8. Shahidi S, Shakibafard A, Zamiri B, Mokhtare MR, Houshyar M, Mahdian S., The Feasibility of Ultrasonography in Defining the Size of Jaw Osseous Lesions. J Dent (Shiraz), 2015; 16: 335-40.

9. Hayashi T, Application of ultrasonography in dentistry. JpnDentSciRev, 2012; 48: 5-13.

10.Çağlayan $F$, Bayrakdar iş, Yılmaz AB, Çenelerde görülen kemik içi lezyonlarda ultrasonografi kullanımı. Turkiye Klinikleri J Oral MaxillofacRadiolSpecialTopics 2016: 2; 3 .

11.Sumer AP, Danaci M, Ozen Sandikçi E, Sumer M, Celenk $P$ Ultrasonography and Doppler ultrasonography in the evaluation of intraosseous lesions of the jaws. Dentomaxillofac Radiol, 2009; 38: 23-7.

12. Rajendran, N. and B. Sundaresan, Efficacy of ultrasound and renkli power Doppler as a monitoring tool in the healing of endodontic periapical lesions. J Endod, 2007; 33: 181-6.

13.Bassiony M, Yang J, Abdel-Monem TM, Elmogy S, Elnagdy $M$. Exploration of ultrasonography in assessment of fascial space spread of odontogenic infections. Oral Surg Oral Med Oral Pathol Oral Radiol Endod 2009; 107: 8619.

14. Wakasugi-Sato N, Kodama M, Matsuo K, Ya mamoto $\mathrm{N}$, Oda M, Ishikawa $A$, et al. Advanced clinical usefulness of ultrasonography for diseases in oral and maxillofacial regions. Int J Dent, 2010; 639382.
15.Goel S, Nagendrareddy SG, Raju MS, Ultrasonography with renkli Doppler and power Doppler in the diagnosis of periapical lesions. Indian J Radiol Imaging, 2011; 21: 279-83.

16. Raghav, N. Reddy, S. S. Giridhar, A. G. Murthy, S. Yashodha Devi, B. K. Santana, N. et al. Comparison of the efficacy of conventional radiography, digital radiography, and ultrasound in diagnosing periapical lesions. Oral Surg Oral Med Oral Pathol Oral Radiol Endod 2010; 110: 379-85.

17. Hussain A , O.I., Dhingra K., Assessment of efficacy of ultrasound in the diagnosis of periapical pathologies. Int $\mathrm{J}$ Com Health and Med Res, 2017; 3: 20-23.

18. Tiwari B, K.M., Popli M, lyer SR, Arora V. Ultrasonography and renkli doppler in the differancial diagnosis of periapical cyst and granuloma. J Contemp Dent 2014; 4: 17-21.

19. Tikku AP, Bharti R, Sharma N, Chandra A, Kumar $A$, Kumar $S$. Dimensional and volumetric analysis of the oropharyngeal region in obstructive sleep apnea patients: A cone beam computed tomography study. Dent Res J (Isfahan), 2016; 13: 396-404.

20. Tikku AP, Kumar S, Loomba K, Chandra A, Verma $P$, Aggarwal R. Use of ultrasound, color Doppler imaging and radiography to monitor periapical healing after endodontic surgery. J Oral Sci. 2010; 52: 411-6.

Yazışma Adresi:

Meryem ETÖZ

Erciyes Üniversitesi Diş Hekimliği Fakültesi

Ağız Diş ve Çene Radyolojisi Ana Bilim Dalı 38039, Melikgazi, Kayseri

Tel : : +90 3522076666 / 29227

Faks : +903524380657

E Posta: meryemetoz@hotmail.com 